\title{
MATÉRIA SECA, PROTEÍNA BRUTA, NITROGÊNIO AMONIACAL E PH DAS SILAGENS DE TRÊS GENÓTIPOS DE MILHETO [Pennisetum glaucum (L). R. BR.] EM DIFERENTES PERÍODOS DE FERMENTAÇÃO
}

\author{
ROBERTO GUIMARÃES JÚNIOR ${ }^{1}$, LÚCIO CARLOS GONÇALVES ${ }^{2}$, JOSÉ AVELINO SANTOS \\ RODRIGUES ${ }^{3}$, DIOGO GONZAGA JAYME ${ }^{4}$, DANIEL ANANIAS DE ASSIS PIRES ${ }^{4}$, ANA LUIZA \\ COSTA CRUZ BORGES ${ }^{2}$, NORBERTO MÁRIO RODRIGUEZ², ELOÍSA OLIVEIRA SIMÕES \\ SALIBA $^{2}$, IRAN BORGES ${ }^{2}$
}

\begin{abstract}
1 Médico Veterinário, Doutorando em Ciência Animal na EV-UFMG. Escola de Veterinária da UFMG. AV. Antônio Carlos 6627, Pampulha. Belo Horizonte/MG - CEP: 30123-970.Tel: 3499-21-91, robertogjunior@hotmail.com 2 Professor do Departamento de Zootecnia da Escola de Veterinária da UFMG. AV. Antônio Carlos 6627, Pampulha. Belo Horizonte/MG - CEP: 30123-970.

3 Pesquisador da Embrapa Milho e Sorgo, Caixa Postal 151. CEP: 35701-970. Sete Lagoas/MG.

4 Médico Veterinário, Doutorando em Ciência Animal na EV-UFMG. Escola de Veterinária da UFMG. AV. Antônio Carlos 6627, Pampulha. Belo Horizonte/MG - CEP: 30123-970.
\end{abstract}

Revista Brasileira de Milho e Sorgo, v.4, n.2, p.251-258, 2005

RESUMO: Os teores de matéria seca (MS), proteína bruta (PB), nitrogênio amoniacal $\left(\mathrm{N}-\mathrm{NH}_{3}\right)$ e $\mathrm{pH}$ foram determinados no material original e nas silagens de três genótipos de milheto, após 1, 3, 5, 7, 14, 28 e 56 dias de fermentação, em silos de laboratório. Os teores de MS das silagens variaram de 23,12 a 24,49\%. Os valores médios da PB foram de 10,95\% nos materiais originais e 10,40\% nas silagens, no $56^{\circ}$ dia. No último período de avaliação os valores médios de $\mathrm{N}_{-} \mathrm{NH}_{3}$ e $\mathrm{pH}$ das silagens foram, respectivamente de $8,75 \%$ e 3,62 . Os teores de matéria seca e proteína bruta não sofreram mudanças significativas ao longo do processo fermentativo $(\mathrm{P}>0,05)$. Houve um aumento nos valores de nitrogênio amoniacal ao longo dos dias de abertura, sem tendência de estabilização. Já os valores de pH estabilizaram-se após 14 dias de fermentação.

Palavras-chave: valor nutricional, silagem, ruminantes, milheto

\section{DRY MATTER, CRUDE PROTEIN, AMMONIACAL NITROGEN AND PH OF THREE PEARL MILLET GENOTYPES SILAGES [Pennisetum glaucum (L). R. BR.] IN DIFFERENT FERMENTATION PERIODS}

\begin{abstract}
The dry matter (DM), crude protein (CP), ammoniacal nitrogen $\left(\mathrm{N}-\mathrm{NH}_{3}\right)$ and $\mathrm{pH}$ values were determined in three pearl millet genotypes silage, after 1, 3, 5, 7, 14, 28 and 56 days ensiling in PVC laboratory silos. Dry matter contents of silage ranged from 23.12 to $24.49 \%$; CP mean levels were $10.95 \%$ for green forages and $10.40 \%$ for silage in the $56^{\text {th }}$ day. In the last evaluation period the $\mathrm{N}_{-} \mathrm{NH}_{3}$ and $\mathrm{pH}$ mean values were $8.75 \%$ and 3.62, respectively. DM and $\mathrm{CP}$ contents remained constant $(\mathrm{P}>0.05)$ and the
\end{abstract}


$\mathrm{N}-\mathrm{NH}_{3}$ values significantly increased, not tending to stability, along the whole fermentation process. However, $\mathrm{pH}$ values stabilized after 14 days ensiling.

Key Words: nutritional value, silage, ruminants, pearl millet

Diversas gramíneas podem ser utilizadas para a produção de silagem, sendo as culturas de milho e sorgo apresentadas como as espécies mais adaptadas ao processo de ensilagem (Zago, 1991). Entretanto, com a finalidade de conhecer alimentos alternativos, torna-se necessário o estudo de novas opções forrageiras produtivas e adaptadas à produção de silagem de boa qualidade.

O milheto [Pennisetum glaucum (L). R. Br.] é uma gramínea originária da África, que apresenta grande potencial forrageiro, pelo seu alto valor nutritivo e sua grande versatilidade de utilização. $\mathrm{Na}$ alimentação de ruminantes, pode ser utilizado sob pastejo contínuo ou rotacionado, na forma de capineira, feno, silagem e grão. É uma planta muito apreciada pelo gado, nutritiva e não possui fatores antinutricionais, como os cianogênicos (Costa, 1992; Lima et al., 1999).

Caracteriza-se por ser uma gramínea anual de verão, de ciclo curto e se destaca como forrageira por sua tolerância ao déficit hídrico, pelo crescimento rápido, boa capacidade de rebrote e boa qualidade como forragem (Bogdan, 1977; Lima et al., 1999; Bonamigo, 1999), sendo considerada uma boa opção para produção de silagem em regiões com problemas de veranico ou seca ou em plantios de sucessão ou safrinha (Andrade \& Andrade, 1982; Pereira et al., 1993).

Este trabalho teve como objetivo determinar o perfil de fermentação das silagens de três genótipos de milheto, por meio da avaliação dos teores de matéria seca, proteína bruta, $\mathrm{pH}$ e nitrogênio amoniacal em percentagem do nitrogênio total.

\section{Material e Métodos}

Os três genótipos de milheto (CMS-1, BRS-1501 e BN-2) utilizados neste experimento foram plantados na área experimental da Embrapa Milho e Sorgo em Sete Lagoas, Minas Gerais. Os materiais foram plantados no mês de março de 1998, em parcelas experimentais de 5,0 $\mathrm{m} \mathrm{x}$ $4,5 \mathrm{~m}$, utilizando-se quatro fileiras por tratamento, com cinco metros de comprimento, espaçadas em 0,90 m e área útil total de $18 \mathrm{~m}^{2}$. Cada genótipo foi plantado em quatro parcelas, que constituíram as suas repetições. A colheita foi realizada após 82 dias de plantio, com os grãos em estádio leitoso. Em seguida, os materiais foram picados em picadeira estacionária, em partículas de aproximadamente $2 \mathrm{~mm}$, homogeneizados manualmente e ensilados em silos de laboratório, confeccionados com tubos de PVC, dotados de válvulas do tipo Bünsen. Uma amostra representativa do material picado foi retirada, para ser, posteriormente, analisada como material original.

A abertura dos silos foi realizada com um, três, cinco, sete, 14, 28 e 56 dias após a ensilagem. Uma parte do material foi pesada e levada à estufa de ventilação forçada, por 72 horas, para determinação da matéria pré-seca (MS) a $65^{\circ} \mathrm{C}$ (AOAC, 1980). O material restante foi prensado em prensa hidráulica Carver, modelo $\mathrm{C}$, para a extração do suco da silagem, tendo sido determinados os valores de $\mathrm{pH}$ e nitrogênio amoniacal em percentagem do nitrogênio total. Nas amostras pré-secas dos materiais originais e das silagens, foram determinados os teores de matéria seca em estufa a $105^{\circ} \mathrm{C}$ e proteína bruta (PB), pelo método de Kjeldhal (AOAC, 1980). 
O delineamento estatístico utilizado foi o inteiramente casualizado, com três tratamentos (genótipos) e quatro repetições (parcelas). Para as variáveis MS e PB, adotou-se um esquema fatorial $3 \times 8$ (genótipos $\times$ material original + dias de abertura) e, para as variáveis $\mathrm{pH}$ e nitrogênio amoniacal, um esquema fatorial 3 x 7 (genótipos x dias de abertura). Os dados foram submetidos à análise de variância, adotando-se o software "SAEG" versão 7.0, 1997, sendo as médias comparadas pelo teste de "Student Newman Kells" (SNK), a 5\% de probabilidade.

\section{Resultados e Discussão}

Os valores de matéria seca no material original e na silagem dos três genótipos de milheto estão apresentados na Tabela 1. Estes variaram de 23,08 para o material original (BN2) a 24,49\%, para o genótipo CMS-1, após um dia de ensilagem. Não foram observadas alterações significativas nos teores de matéria seca entre os materiais originais e as silagens, entre os diferentes tempos de ensilagem, para o mesmo genótipo, e também na comparação entre genótipos numa mesma época. A não redução dos teores de matéria seca ao longo da ensilagem também foi verificada por Rocha Júnior (1999), que trabalhou com sete genótipos de sorgo.
Chaves (1997) obteve um valor médio de matéria seca para silagem de milheto de 27,7\%. Seiffert \& Prates (1978), avaliando o material original e a silagem de milheto após 40 dias de fermentação, observaram valores bem menores para a matéria seca de duas cultivares de milheto no material original (11,9 e 9,32\%) e, para as silagens, a cultivar Comum apresentou valor similar ao obtido neste experimento, de 23,00\% MS, e ao obtido por Messman et al. (1992) (23,4\% MS). A cultivar AO64 apresentou $32,50 \%$ de matéria seca, valor maior do que os geralmente relatados para silagens dessa forrageira.

Os valores de matéria seca encontrados para as silagens dos genótipos de milheto CMS1, BRS-1501 e BN-2, aos 56 dias após a ensilagem, são inferiores aos obtidos para silagens de outras culturas (Tomich, 1999; Antunes, 2001; Araújo, 2002; Pereira 2003); esse fato pode ser justificado pelas características particulares de cada cultura e pela época de corte do milheto para a ensilagem, aos 82 dias, quando os grãos estavam em estádio leitoso. Nesse período, a planta do milheto apresentava um baixo conteúdo de matéria seca, o que influiu diretamente sobre os teores de matéria seca das silagens produzidas.

Os valores de proteína bruta do material original e das silagens, apresentados na

TABELA 1. Matéria seca (\%) no material original (MO) e nas silagens de três genótipos de milheto, após diferentes períodos de fermentação

\begin{tabular}{lcccccccc}
\hline & & \multicolumn{7}{c}{ Dias após a ensilagem } \\
\cline { 3 - 8 } Genótipo & MO & $\mathbf{1}$ & $\mathbf{3}$ & $\mathbf{5}$ & $\mathbf{7}$ & $\mathbf{1 4}$ & $\mathbf{2 8}$ & $\mathbf{5 6}$ \\
\hline CMS-1 & $23,36 \mathrm{Aa}$ & $24,49 \mathrm{Aa}$ & $23,96 \mathrm{Aa}$ & $23,84 \mathrm{Aa}$ & $23,66 \mathrm{Aa}$ & $24,46 \mathrm{Aa}$ & $23,89 \mathrm{Aa}$ & $23,91 \mathrm{Aa}$ \\
BRS-1501 & $23,08 \mathrm{Aa}$ & $24,03 \mathrm{Aa}$ & $23,72 \mathrm{Aa}$ & $23,08 \mathrm{Aa}$ & $23,12 \mathrm{Aa}$ & $23,58 \mathrm{Aa}$ & $24,19 \mathrm{Aa}$ & $23,28 \mathrm{Aa}$ \\
BN-2 & $23,08 \mathrm{Aa}$ & $23,48 \mathrm{Aa}$ & $23,57 \mathrm{Aa}$ & $23,63 \mathrm{Aa}$ & $22,64 \mathrm{Aa}$ & $24,01 \mathrm{Aa}$ & $23,75 \mathrm{Aa}$ & $23,59 \mathrm{Aa}$ \\
\hline Média & $23,17 \mathrm{~A}$ & $24,00 \mathrm{~A}$ & $23,75 \mathrm{~A}$ & $23,52 \mathrm{~A}$ & $23,14 \mathrm{~A}$ & $24,01 \mathrm{~A}$ & $23,94 \mathrm{~A}$ & $23,59 \mathrm{~A}$ \\
\hline
\end{tabular}

Médias seguidas por letras maiúsculas iguais, na mesma linha, não diferem estatisticamente. Médias seguidas por letras minúsculas iguais, na mesma coluna, não diferem estatisticamente. Teste $\mathrm{SNK}, \mathrm{p}<0,05, \mathrm{CV}=4,04 \%$. 
Tabela 2, variaram de 9,59\%, para o genótipo CMS-1, na abertura do dia 14 até $11,68 \%$ para o genótipo BRS-1501, no material original. Os níveis de proteína bruta encontrados neste experimento são superiores aos normalmente encontrados na planta fresca e nas silagens de outras culturas utilizadas para a produção de silagem, indicando que o valor nutricional da silagem de milheto é superior, quando relacionado ao seu conteúdo protéico. Antunes (2001) encontrou valores entre 7,65 e 8,64\%, em milho, Araújo (2002) obteve valores variando de 7,39 a 7,64\%, em sorgo, e Pereira (2003) relatou teores de proteína bruta variando entre 7,6 e 9,8\%, em girassol.

Quando os genótipos foram comparados no material original e nos tempos de fermentação, quanto ao teor de proteína, o BRS-1501 foi superior aos demais, indicando o seu maior valor nutricional. Nos diferentes tempos de abertura, o maior valor numérico encontrado para esse genótipo foi no $56^{\circ}$ dia $(11,32 \%)$. Os genótipos CMS-1 e BN-2 foram semelhantes estatisticamente $(p>0,05)$ quanto ao material original e ao longo de todo o processo fermentativo. Nos diferentes dias de fermentação os maiores valores encontrados para esses genótipos foram 10,49\%, no $7^{\circ}$ dia, e $10,27 \%$, no $28^{\circ}$ dia, do CMS- 1 e BN2 , respectivamente. Dentro do mesmo genótipo não foram observadas quedas acentuadas nos valores de proteína bruta, com exceção do CMS1 no $14^{\circ}$ dia. Isto mostra que o teor de proteína bruta manteve-se estável ao longo do processo fermentativo, sofrendo pouca influência dos processos proteolíticos que normalmente ocorrem dentro do silo, e que os níveis de nitrogênio total da forragem fresca não sofreram modificações com a ensilagem, embora a fermentação possa ter alterado as proporções das frações nitrogenadas (Van Soest, 1994).

Os elevados níveis de proteína bruta verificados para o milheto são de grande importância na nutrição de ruminantes, pois garantem uma fermentação microbiana efetiva no rúmen, levando em consideração os valores mínimos de 7\% de proteína bruta na dieta como requisitos para uma fermentação adequada (Church, 1988).

Os valores de nitrogênio amoniacal como percentagem do nitrogênio total encontram-se na Tabela 3. Os teores variaram de 3,32, para o genótipo $\mathrm{BN}-2$, no $1^{\circ}$ dia, até $9,01 \%$, para o genótipo BRS-1501, no $56^{\circ}$ dia de fermentação. O valor médio de $8,75 \%$ encontrado para as silagens dos três genótipos de milheto, aos 56 dias de fermentação, é superior ao obtido por Machado Filho \& Mühlbach (1986), que encontraram o valor de 6,22 para silagem de milheto sem emurchecimento. Aos 56 dias de fermentação, Antunes (2001) obteve valores que variaram

TABELA 2. Proteína bruta (\% da matéria seca) no material original (MO) e nas silagens de três genótipos de milheto, após diferentes períodos de fermentação

\begin{tabular}{lcccccccc}
\hline & & \multicolumn{7}{c}{ Dias após a ensilagem } \\
\cline { 3 - 9 } Genótipo & MO & $\mathbf{1}$ & $\mathbf{3}$ & $\mathbf{5}$ & $\mathbf{7}$ & $\mathbf{1 4}$ & $\mathbf{2 8}$ & $\mathbf{5 6}$ \\
\hline CMS-1 & $10,65 \mathrm{Ab}$ & $10,23 \mathrm{ABb}$ & $10,06 \mathrm{ABb}$ & $10,20 \mathrm{ABb}$ & $10,49 \mathrm{ABb}$ & $9,59 \mathrm{Bb}$ & $9,96 \mathrm{ABb}$ & $10,15 \mathrm{ABb}$ \\
BRS-1501 & $11,68 \mathrm{Aa}$ & $10,96 \mathrm{Aa}$ & $10,82 \mathrm{Aa}$ & $10,96 \mathrm{Aa}$ & $11,25 \mathrm{Aa}$ & $10,91 \mathrm{Aa}$ & $11,25 \mathrm{Aa}$ & $11,32 \mathrm{Aa}$ \\
BN-2 & $10,51 \mathrm{Ab}$ & $9,68 \mathrm{Ab}$ & $10,08 \mathrm{Ab}$ & $9,82 \mathrm{Ab}$ & $9,92 \mathrm{Ab}$ & $9,87 \mathrm{Ab}$ & $10,27 \mathrm{Ab}$ & $9,73 \mathrm{Ab}$ \\
\hline Média & $10,95 \mathrm{~A}$ & $10,29 \mathrm{~B}$ & $10,32 \mathrm{~B}$ & $10,33 \mathrm{~B}$ & $10,55 \mathrm{~B}$ & $10,12 \mathrm{~B}$ & $10,49 \mathrm{~B}$ & $10,40 \mathrm{~B}$ \\
\hline
\end{tabular}

Médias seguidas por letras maiúsculas iguais, na mesma linha, não diferem estatisticamente. Médias seguidas por letras minúsculas iguais, na mesma coluna, não diferem estatisticamente. Teste $\mathrm{SNK}, \mathrm{p}<0,05, \mathrm{CV}=4,27 \%$. 
TABELA 3. Nitrogênio amoniacal em relação ao nitrogênio total (\% da matéria seca) das silagens de três genótipos de milheto, após diferentes períodos de fermentação

\begin{tabular}{lccccccc}
\hline & \multicolumn{7}{c}{ Dias após a ensilagem } \\
\cline { 2 - 8 } Genótipo & $\mathbf{1}$ & $\mathbf{3}$ & $\mathbf{5}$ & $\mathbf{7}$ & $\mathbf{1 4}$ & $\mathbf{2 8}$ & $\mathbf{5 6}$ \\
\hline CMS-1 & $3,39 \mathrm{Ea}$ & $5,09 \mathrm{Da}$ & $5,06 \mathrm{Da}$ & $6,16 \mathrm{Ca}$ & $6,32 \mathrm{Ca}$ & $7,7 \mathrm{Ba}$ & $8,46 \mathrm{Aa}$ \\
BRS-1501 & $3,50 \mathrm{Fa}$ & $5,20 \mathrm{Ea}$ & $5,82 \mathrm{DEa}$ & $6,26 \mathrm{CDa}$ & $6,71 \mathrm{BCa}$ & $7,27 \mathrm{Ba}$ & $9,01 \mathrm{Aa}$ \\
BN-2 & $3,32 \mathrm{Ea}$ & $5,15 \mathrm{Da}$ & $5,87 \mathrm{Ca}$ & $6,27 \mathrm{Ca}$ & $6,22 \mathrm{Ca}$ & $7,27 \mathrm{Ba}$ & $8,79 \mathrm{Aa}$ \\
\hline Média & $3,4 \mathrm{~F}$ & $5,15 \mathrm{E}$ & $5,59 \mathrm{D}$ & $6,23 \mathrm{C}$ & $6,42 \mathrm{C}$ & $7,41 \mathrm{~B}$ & $8,75 \mathrm{~A}$ \\
\hline
\end{tabular}

Médias seguidas por letras maiúsculas iguais, na mesma linha, não diferem estatisticamente. Médias seguidas por letras minúsculas iguais, na mesma coluna, não diferem estatisticamente. Teste $\mathrm{SNK}, \mathrm{p}<0,05, \mathrm{CV}=8,12 \%$.

entre 5,60 e 6,89\%, Pereira (2003) obteve de 5,8 a $9,4 \%$ e Rocha Júnior (1999) de 3,81 a $6,32 \%$, para silagens de milho, girassol e sorgo, respectivamente. Valores inferiores foram encontrados por Chaves (1997), de 2,96\% para silagem de milheto, $2,79 \%$, para silagem de capim Sudão, 1,68\% para silagem de milho e $1,54 \%$ para silagem de teosinto.

Quando comparados numa mesma época de ensilagem, os genótipos não diferiram estatisticamente. Entretanto, houve um aumento nos valores de nitrogênio amoniacal ao longo dos dias de abertura, sem tendência de estabilização, demonstrando a necessidade de avaliação das silagens de milheto em períodos superiores a 56 dias de fermentação. Desta forma, os maiores valores de nitrogênio amoniacal em percentagem do nitrogênio foram observados no último dia de fermentação ( $56^{\circ}$ dia $)$.

O efeito do tempo de fermentação sobre o aumento nos teores de nitrogênio amoniacal
$(\%)$ foi cúbico $(\mathrm{p}<0,05)$, conforme as seguintes equações de regressão:

CMS- $1=3,557+0,372 \mathrm{X}-0,0113 \mathrm{X}^{2}+0,000111 \mathrm{X}^{3}\left(\mathrm{r}^{2}=0,87\right)$ BRS-1501 $=3,580+0,468 X-0,0177 X^{2}+0,000199 X^{3}\left(r^{2}=0,89\right)$ $\mathrm{BN}-2=3,621+0,424 \mathrm{X}-0,0116 \mathrm{X}^{2}+0,000172 \mathrm{X}^{3}\left(\mathrm{r}^{2}=0,78\right)$

Os valores de nitrogênio amoniacal em percentagem do nitrogênio total obtidos para as silagens de milheto no final do período de fermentação podem ser considerados baixos, demonstrando uma baixa redução nos níveis de proteína verdadeira ao longo da fermentação. De acordo com Oshima \& McDonald (1978), AFRC (1987) e Henderson (1993), para que uma silagem seja considerada de boa qualidade, os níveis de

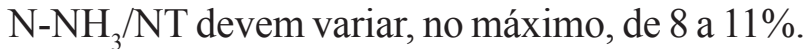
Segundo a classificação proposta por Benachio (1965) e pelo AFRC (1987), as silagens de milheto estudadas seriam consideradas como muito boa e de boa qualidade, respectivamente.

$\mathrm{Na}$ Tabela 4, são mostrados os valores de $\mathrm{pH}$ no suco da silagem. As variações de $\mathrm{pH}$

TABELA 4. Potencial de hidrogênio $(\mathrm{pH})$ das silagens de três genótipos de milheto, após diferentes períodos de fermentação

\begin{tabular}{lccccccc}
\hline & \multicolumn{7}{c}{ Dias após a ensilagem } \\
\cline { 2 - 7 } Genótipo & $\mathbf{1}$ & $\mathbf{3}$ & $\mathbf{5}$ & $\mathbf{7}$ & $\mathbf{1 4}$ & $\mathbf{2 8}$ & $\mathbf{5 6}$ \\
\hline CMS-1 & $5,08 \mathrm{Aab}$ & $4,32 \mathrm{Ba}$ & $3,94 \mathrm{Ca}$ & $3,88 \mathrm{Cab}$ & $3,67 \mathrm{Db}$ & $3,60 \mathrm{Db}$ & $3,58 \mathrm{Db}$ \\
BRS-1501 & $5,13 \mathrm{Aa}$ & $4,13 \mathrm{Bb}$ & $4,00 \mathrm{Ca}$ & $3,96 \mathrm{Ca}$ & $3,83 \mathrm{Da}$ & $3,75 \mathrm{Da}$ & $3,72 \mathrm{Da}$ \\
BN-2 & $4,99 \mathrm{Ab}$ & $3,97 \mathrm{Bc}$ & $3,89 \mathrm{BCa}$ & $3,79 \mathrm{Cb}$ & $3,66 \mathrm{Db}$ & $3,58 \mathrm{Db}$ & $3,56 \mathrm{Db}$ \\
\hline Média & $5,07 \mathrm{~A}$ & $4,14 \mathrm{~B}$ & $3,94 \mathrm{C}$ & $3,88 \mathrm{D}$ & $3,72 \mathrm{E}$ & $3,64 \mathrm{~F}$ & $3,62 \mathrm{~F}$ \\
\hline
\end{tabular}

Médias seguidas por letras maiúsculas iguais, na mesma linha, não diferem estatisticamente. Médias seguidas por letras minúsculas iguais, na mesma coluna, não diferem estatisticamente. Teste $\mathrm{SNK}, \mathrm{p}<0,05, \mathrm{CV}=1,78 \%$. 
foram de 3,56, para o BN-2, aos 56 dias de fermentação, até 5,13 , para o BRS-1501, no $1^{\circ}$ dia de abertura. No $56^{\circ}$ dia de abertura, o valor médio encontrado para os três genótipos foi de 3,62. Os valores de $\mathrm{pH}$ das silagens dos genótipos estudados são inferiores aos obtidos por Andrade e Andrade (1982), de 5,30, aos 68 dias, e encontram-se dentro da faixa descrita por Machado Filho e Mühlbach (1986), que vai de 3,53 a 5,91, em silagens de milheto. Quando comparada com silagens de outras culturas, a silagem de milheto também apresentou menores valores de $\mathrm{pH}$. Para silagens de milho, sorgo e girassol, valores médios de $\mathrm{pH}$, aos 56 dias de fermentação, foram, respectivamente, de 3,76 (Antunes, 2001), 3,77 (Rocha Júnior, 1999) e 4,8 (Pereira, 2003).

Os valores do $\mathrm{pH}$ diminuíram à medida que avançavam os dias após a ensilagem, sendo a queda mais pronunciada verificada até o $3^{\circ}$ dia . Nas aberturas dos $5^{\circ}$ e $7^{\circ}$ dias, houve quedas de $\mathrm{pH}$ menos acentuadas. A partir do $14^{\circ}$ dia os valores de $\mathrm{pH}$ estabilizaram-se, sendo esta a dinâmica observada para todas as cultivares estudadas. A partir do $7^{\circ}$ dia , o híbrido BRS-1501 firmou-se como aquele com valor de $\mathrm{pH}$ mais elevado, em relação aos demais, que foram estatisticamente semelhantes entre si.

De acordo com Muck (1988), o pH normalmente declina nos primeiros cinco dias de ensilagem. Freire (2001) e Pereira (2003), estudando o perfil de fermentação de silagens de girassol, e Brito (1999), trabalhando com silagem de sorgo, também observaram estabilização dos valores de $\mathrm{pH}$ por volta do $14^{\circ}$ dia. Já Antunes (2001) observou estabilização desses valores a partir do $5^{\circ}$ dia, para silagens de quatro híbridos de milho, e Bernardino (1996) e Rocha Júnior (1999), a partir do sétimo dia, para silagens de sorgo. A redução de $\mathrm{pH}$ mais acentuada poucos dias após a ensilagem do material pode ser um indicativo de que a maioria dos processos fermentativos que devem ocorrer dentro do silo acontecem logo nos primeiros dias pós-fechamento. Esse fato é de grande importância na produção de silagens de qualidade, principalmente naquelas com baixos teores de matéria seca, reduzindo a proteólise e a atividade clostridiana dentro do silo (Muck, 1988).

\section{Conclusões}

Os genótipos de milheto estudados mostraram-se estáveis durante o processo fermentativo, com relação aos teores de matéria seca e proteína bruta. No entanto, mais estudos são necessários para se avaliar o efeito do tempo de ensilagem sobre os níveis de nitrogênio amoniacal dessas silagens.

De acordo com os resultados obtidos, o melhor período para utilização da silagem de milheto se dá por volta de 14 dias após a ensilagem.

\section{Referências Bibliografias}

AFRC technical committee on responses to nutrients. Report n.2. Characterization of feedstuffs: nitrogen. Nutrition Abstract and Reviews, Ser. B, Wallingford, v. 57, n. 12, p. 713736, 1987.

ANDRADE, J. B.; ANDRADE, P. Produção de silagem de milheto (Pennisetum americanum (L.) K. Schum.). Boletim da Indústria Animal, Nova Odessa, v. 39, n. 1, p. 67-73, 1982.

ANTUNES, R. C. Padrão de fermentação das silagens de seis genótipos de milho (Zea mays L.)., 2001. 50 f. Dissertação (Mestrado em Zootecnia) - Escola de Veterinária, Universidade Federal de Minas Gerais, Belo Horizonte.

ARAÚJO, V. L. Momento de colheita de três genótipos de sorgo para a produção de silagem. 
2002. 47 f. Dissertação (Mestrado em Zootecnia) - Escola de Veterinária, Universidade Federal de Minas Gerais, Belo Horizonte.

BENACHIO, S. Niveles de melaza em silo experimental de milho crillo (Sorghum vulgare). Agronomia Tropical, Maracay, v. 14, n. 2, p. 291-297, 1965.

BERNARDINO, M. L. A. Avaliação de silagens de híbridos de sorgo [Sorghum bicolor (L) Moench] de porte médio com diferentes teores de taninos e suculência no colmo. 1996. 87 f. Dissertação (Mestrado em Zootecnia) - Escola de Veterinária, Universidade Federal de Minas Gerais, Belo Horizonte.

BOGDAN, A. V. Tropical pasture and fodder plants (Grasses and Legumes). London: Longman, 1977. 241 p. (Tropical Agricultural Series)

BONAMIGO, L. A. A cultura do milheto no Brasil, Implantação e desenvolvimento no cerrado. In: WORKSHOP INTERNACIONAL DE MILHETO, 1999, Brasília, DF. Anais... Planaltina: Embrapa Cerrados, 1999. p. 3165.

BRITO, A. F Avaliação das silagens de sete genótipos de sorgo (Sorghum bicolor (L) Moench) e os seus padrões de fermentação. 1999. 129 F. Dissertação (Mestrado em Zootecnia) - Escola de Veterinária, Universidade Federal de Minas Gerais, Belo Horizonte.

CHAVES, C. Produção e valor nutritivo das silagens de capim sudão [Sorghum sudanense (Piper) Stapf, milheto (Pennisetum americanum (L.) Leeke], teosinto (Euchlaena mexicana Schrad) e milho (Zea mays L.).1997. 56 f. Dissertação (Mestrado em Zootecnia) Universidade Federal de Lavras, Lavras..
CHURCH, D.C. The ruminant animal digestive physiology and nutrition. New Jersey: Prentice Hall, 1988. 564 p.

COSTA, N. L. Estabelecimento, formação e manejo de pastagens de milheto. Lavoura Arrozoeira, Porto Alegre, v. 45, n. 405, p. 7-72, 1992.

FREIRE, E. M. Padrão de fermentação das silagens de cinco híbridos de girassol. 2001. 44 f. Dissertação (Mestrado em Zootecnia) - Escola de Veterinária, Universidade Federal de Minas Gerais, Belo Horizonte.

HENDERSON, N. Silage additives. Animal Feed Science and Technology, Amsterdam, v. 45, n. 1, p. 35-56, 1993.

HORWITZ,W. (Ed.). Official methods of analysis of the Association of Official Analytical Chemists. 13. ed. Washington: Association of Official Analytical Chemists, 1980. $1080 \mathrm{p}$.

LIMA, M. L. M.; CASTRO, F. G. F.; TAMASSIA, L. F. M. Culturas não-convencionais - girassol e milheto. In: SIMPOSIO SOBRE NUTRIÇÃO DE BOVINOS, 7., 1999, Piracicaba. Alimentação suplementar: anais... Piracicaba: FEALQ, 1999. p. 178-195.

MACHADO FILHO, L. C. P.; MÜHLBACH, P. R.F. Efeito do emurchecimento na qualidade das silagens de Capim - Elefante (Pennisetum purpureum Schumach.) e de Milheto (Pennisetum americanum (1.) Leeke), avaliadas quimicamente. Revista da Sociedade Brasileira de Zootecnia, Viçosa, v.15, n. 3, p. 224-233, 1986.

MESSMAN, M.; WEISS W. P.; HENDERLONG, P. R.; SHOCKEY, W. L. Evaluation of Pearl Millet and Field Peas Plus 
Triticale Silages for Midlactation Dairy Cows. Journal of Dairy Science, Champaign, v. 75, n. 10, p. 2759-2775, 1992.

MUCK, R.E. Factors Influencing Silage Quality and Their Implications for Manegement. Journal of Dairy Science, Champaign, v. 71, p. 29923002, 1988.

OHSHIMA, M.; McDONALD, P. A Review of Changes in Nitrogenous compounds in herbages during ensiling. Journal of the Science of Food and Agriculture, London, v. 29, n. 6, p. 497505, 1978.

PEREIRA, L. G. R. Potencial forrageiro da cultura do girassol (Helianthus annuus L.) para a produção de silagem. 2003. 134 f. Dissertação (Doutorado em Ciência Animal) - Escola de Veterinária, Universidade Federal de Minas Gerais, Belo Horizonte.

PEREIRA, O. G.; OBEID, J. A; GOMIDE, J. A.; QUEIROZ, A. C.; FILHO, S. C. V. Produtividade e valor nutritivo de aveia (Avena sativa), milheto (Pennisetum americanum) e de um híbrido de Sorghum bicolor X S. sudanense. Revista da Sociedade Brasileira de Zootecnia, Viçosa, v. 22, n. 1, p. 22-30, 1993.
ROCHA JÚNIOR, V. R. Qualidade das silagens de sete genótipos de sorgo (Sorghum bicolor L. Moench) e seus padrões de fermentação. 1999. 132 f. Dissertação (Mestrado em Zootecnia) - Escola de Veterinária, Universidade Federal de Minas Gerais, Belo Horizonte.

SEIFFERT, N. F.; PRATES, E. R. Forrageiras para a ensilagem. II - Valor Nutritivo e Qualidade de Silagem de Cultivares de Milho (Zea mays, L.), Sorgos (Sorghum sp.) e Milhetos (Pennisetum americanum, Schum). Revista da Sociedade Brasileira de Zootecnia, Viçosa, v. 7, n. 2, p. 183-195, 1978.

TOMICH, T. R. Avaliação do potencial forrageiro das silagens de treze cultivares de girassol (Heliantus annuus L.). 1999. $131 \mathrm{f}$. Dissertação (Mestrado em Zootecnia) - Escola de Veterinária, Universidade Federal de Minas Gerais, Belo Horizonte.

VAN SOEST, P.J. Nutritional ecology of the ruminant. 2. ed. Ithaca: Cornell University Press, 1994. $476 \mathrm{p}$.

ZAGO, C. P. Cultura de sorgo para produção de silagem de alto valor nutritivo. Capinópolis: Sementes Agroceres, 1991. 34 p. 